\title{
Correction: Large-Scale Evidence for the Effect of the COLIA1 Sp1 Polymorphism on Osteoporosis Outcomes: The GENOMOS Study
}

Stuart H. Ralston, André G. Uitterlinden, Maria Luisa Brandi, Susana Balcells, Bente L. Langdahl, Paul Lips, Roman Lorenc, Barbara Obermayer-Pietsch, Serena Scollen, Mariona Bustamante, Lise Bjerre Husted, Alisoun H. Carey, Adolfo Diez-Perez, Alison M. Dunning, Alberto Falchetti, Elzbieta Karczmarewicz, Marcin Kruk, Johannes P. T. M. van Leeuwen, Joyce B. J. van Meurs, Jon Mangion, Fiona E. A. McGuigan, Leonardo Mellibovsky, Francesca del Monte, Huibert A. P. Pols, Jonathan Reeve, David M. Reid, Wilfried Renner, Fernando Rivadeneira, Natasja M. van Schoor, Rachael E. Sherlock, John P. A. loannidis, for the GENOMOS investigators

DOI: 10.1371/journal.pmed.0030090

In PLoS Medicine, volume 3, issue 4:

Among the listed additional authors, J. da Silva, J. Bruges Armas, and A. Lopes Vaz are from Portugal.

This correction note may be found online at DOI: 10.1371/journal.pmed.0030223.

Published May 30, 2006.

Citation: Correction: Large-scale evidence for the effect of the COLIA1 Sp1 polymorphism on osteoporosis outcomes:

The GENOMOS study. PLoS Med 3(4): e223.

\section{Correction: An Immeasurable Crisis? A Criticism of the Millennium Development Goals and Why They Cannot Be Measured}

Amir Attaran

DOI: 10.1371/journal.pmed.0020318

In PLoS Medicine, volume 2, issue 10:

Reference 3 [Deputy Secretary General United Nations (2004) Message to the inter-agency and expert meeting on MDG indicators Geneva 29 September-1 October 2004. New York: United Nations. Available: http://unstats.un.org/unsd/mi/ techgroup/Sept2004/message_to_inter_agency_mdg.pdf. Accessed 1 August 2005] was publicly accessible at the time of publication of Amir Attaran's article, but is no longer publicly accessible. This file can now be found as Text S1.

Text S1.

Deputy Secretary-General's Message to the Inter-Agency and Expert Meeting on MDG Indicators

Found at DOI: 10.1371/journal.pmed.0030224.sd001 (44.5 KB DOC).

This correction note may be found online at DOI: 10.1371/journal.pmed.0030224.

Published May 30, 2006.

Citation: Correction: An immeasurable crisis? A criticism of the Millennium Development Goals and why they cannot

be measured. PLoS Med 3(4): e224.

\section{Correction: Author's Reply}

Amir Attaran

DOI: 10.1371/journal.pmed.0020405

In PLoS Medicine, volume 2, issue 11:

Reference 3 [United Nations (2005) Data availability analysis. New York: United Nations. Available: http://unstats.un.org/ unsd/mi/techgroup/January2005/Series\%20update\%20status\%20query_FC.xls. Accessed 13 October 2005] was publicly accessible at the time of publication of Amir Attaran's article, but is no longer publicly accessible. This file can now be found as Dataset S1.

Dataset S1.

Millennium Indicators Database

Found at DOI: 10.1371/journal.pmed.0030225.sd001 (41.5 KB XLS).

\footnotetext{
This correction note may be found online at DOI: 10.1371/journal.pmed.0030225.

Published May 30, 2006.

Citation: Correction: Author's reply. PLoS Med 3(4): e225.
} 


\section{Correction: Randomized, Controlled Intervention Trial of Male Circumcision for Reduction of HIV Infection Risk: The ANRS 1265 Trial}

Bertran Auvert, Dirk Taljaard, Emmanuel Lagarde, Joëlle Sobngwi-Tambekou, Rémi Sitta, Adrian Puren

DOI: 10.1371/journal.pmed.0020298

In PLoS Medicine, volume 2, issue 11:

Table 4: Under "Religion," the values for "HIV cases," "Follow-up," and "HIV incidence rates" for the categories "Catholic or Protestant" and "Others" were reversed in error. The correct values are as follows.

Catholic or Protestant: HIV cases, 5; Follow-up (py), 576; HIV Incidence Rates (95\% Cl per 100 py), 0.87 (0.33-2.09).

Others: HIV cases, 25; Follow-up (py), 1,845; HIV Incidence Rates (95\% Cl per 100 py), 1.36 (0.92-2.02).

This correction note may be found online at DOI: 10.1371/journal.pmed.0030226.

Published May 30, 2006.

Citation: Correction: Randomized, controlled intervention trial of male circumcision for reduction of HIV infection

risk: The ANRS 1265 trial. PLoS Med 3(5): e226.

\section{Correction: The Latest Mania: Selling Bipolar Disorder}

David Healy

DOI: 10.1371/journal.pmed.0030185

In PLoS Medicine, volume 2, issue 4:

The correct title for Figure 2 should be "Author's Graph of $p$-Value Function Based on Data in [28]." The correct title for Figure S1 should be "Episheet Showing Author's Relative Risk Calculation, Based on Data in [28]."

This correction note may be found online at DOI: 10.1371/journal.pmed.0030236.

Published May 30, 2006.

Citation: Correction: The latest mania: Selling bipolar disorder. PLoS Med 3(5): e236.

\section{Correction: Author's Reply}

Karmela Krleža-Jerić

DOI: 10.1371/journal.pmed.0030167

In PLoS Medicine, volume 3, issue 3:

The URL provided for the Ottawa Group was incorrect. It should be http://ottawagroup.ohri.ca/signatories.html.

This correction note may be found online at DOI: 10.1371/journal.pmed.0030251.

Published May 30, 2006.

Citation: Correction: Author's reply. PLoS Med 3(5): e251. 